\title{
When Bioeconomy Development Becomes a Biomass Energy Competitor
}

\author{
Dace LAUKA ${ }^{1 *}$, Dzintra SLISANE ${ }^{2}$, Linda IEVINA $^{3}$, Indra MUIZNIECE ${ }^{4}$, \\ Dagnija BLUMBERGA ${ }^{5}$ \\ ${ }^{1-5}$ Institute of Energy Systems and Environment, Riga Technical University, Azenes iela 12/1, \\ Riga, LV-1048, Latvia
}

\begin{abstract}
Biomass is an essential pillar of the bioeconomy as it serves as its main resource. Biomass energy plays an important role in energy sector. According to long wave theory, a sharp breakthrough in biotechnology is due over the next few years. As the price for energy wood increases, wood as a resource will not be sustainable in energy sector. In the case of Latvia, the price of energy wood as a resource is predicted to increase from $0.04 \mathrm{EUR} / \mathrm{kWh}$ to $0.12 \mathrm{EUR} / \mathrm{kWh}$ per unit of energy.
\end{abstract}

Keywords - Bioeconomy; bioenergy; energy wood; LCOE; long waves theory

\section{INTRODUCTION}

One of the main requirements for the mitigation of the impact on climate change is the replacement of fossil fuels with renewable energy resources [1], the most popular of which are solar, wind and biomass energy. Each type of renewable energy has its advantages and limitations, related to technological development, costs, environmental pollution, seasonality of exploitation and other circumstances. In this competition between the three above mentioned renewable energy sources, biomass energy plays an important role in energy sector, for it provides a stable energy supply, which does not depend on climate conditions. Therefore, the development of energy plants, which transform the chemical biomass energy into mechanical energy, is rapid and mainly related to implementation of innovative solutions and optimisation of energy efficiency. However, the use of biomass for energy is being increasingly competed by the development of bioeconomy, due to the launch of value-added production in almost all sectors of economy [2]. The issue of biomass energy development, its hindering factors and future prospects become increasingly important. It is the question of constructing biomass energy plants in the near and further future through the development of national energy strategies and action plans.

The aim of this research is to show common issues through the concept of bioeconomy, long wave theory and calculations based on levelized costs of electricity. Long wave theory, predicts that the $5^{\text {th }}$ generation will include biotechnology as driving innovations. The biotechnology development and concept of bioeconomy suggest that in the future wood resources will be used only as a resource for products with high added value. The way the product is processed and the way it interacts with its environmental impact depends on

\footnotetext{
* Corresponding author.

E-mail address: dace.lauka@rtu.lv
}

(C)2019 Dace Lauka, Dzintra Slisane, Linda Ievina, Indra Muizniece, Dagnija Blumberga.

This is an open access article licensed under the Creative Commons Attribution License (http://creativecommons.org/

licenses/by/4.0), in the manner agreed with Sciendo. 
technology. Technological development is promoting the use of resources and the development of the bioeconomy concept.

Blind spots in pathway is defined as from fossil fuels to renewable energy. Energy transitions aim at the economic prosperity through:

- "Green-collar" job creation;

- Greater energy independence;

- Reduced emissions.

These objectives imply creating policy-supported national renewable technology industries, ideally reducing clean energy costs to a point where support becomes unnecessary. Two dimensions of competition arise:

- Renewables competing with incumbent technologies;

- Local renewable technology industries competing with others globally.

The policy can sometimes overlook the evolution of such competitive pressures due to three blind spots. For instance, the policy support may:

- Create demand that exceeds the domestic industry's capacity to expand, which will generate jobs overseas;

- Underestimate the pace at which the costs of a new technology are falling and become inadvertently over-generous;

- Underestimate the innovation potential in incumbent technologies, which necessitates longer-than-anticipated support for the renewable technology or, at worst, cease the support before the new technology is sustainably cost-competitive.

These blind spots suggest that policymakers may incorporate more realistic representations of foreseeable changes in the competitive dynamics of industry and trade into transition planning.

\subsection{Wood as a Resource in Bioeconomics}

Several historical stages in the resource usage development in power sector can be distinguished. At first, for a long time mainly wood was used for energy production because of its wide availability. Later, along with the development of technologies in coal mining and invention of power plants, coal had become an important energy resource. Coal was more efficient for energy, and in the 1780s exceeded the use of wood for the first time. This stage was followed by the development in geological theories and drilling technologies, which had led to a significant increase in oil and gas production. In 1965 oil and gas accounted for more than $50 \%$ of the total produced energy [3].

In Europe the consumption of wood and other solid biomass for energy is increasing every year [4]. The increasing use of energy wood can be linked to economic factors and politics in environmental protection. First, it is important to note that the oil crisis in 1973 and 1979, when oil prices rapidly increased, encouraged the seeking for independence from imported fossil fuels. The oil crisis led to an increasing demand for energy wood and a reduction of wood price [3], [5]. Secondly, in the second half of the 20th century environmental awareness arose, and the presence of environmental problems, including air pollution and depletion of resources, was recognized globally. It was also recognised that fossil fuels not only have especially bad impact on the environment, but can also be depleted. Wood, on the contrary, is a renewable resource and it is considered to be neutral for $\mathrm{CO}_{2}$ and GHG emissions [3], [5], [6]. At the same time the environmental policy of the EU started to develop rapidly, and today it can be seen as the main instrument to regulate the use of resources, a specific driver for the increase of energy [7]. 
Biomass can be seen as the base element of bioeconomy and it serves as its main resource. The largest producer of biomass is the forestry sector. The global production of wood in 2015 was 1.87 billion $\mathrm{m}^{3}, 147$ million $\mathrm{m}^{3}$ or $7.88 \%$ of which was produced in Europe [8]. According to the United Nations Economic Commission's for Europe [9] enquiry for 2015, which contained data from 31 countries in UNECE region, wood resources in UNECE region accounts for $3.8 \%$ of the total amount of energy resources and $37.7 \%$ of renewable resources. Wood residues and by-products from forest industry accounts for $43.5 \%$ of the total consumed energy wood, while $38.2 \%$ accounts for wood, that is obtained directly from forests or wooded areas outside forests [9].

Wood resources consist of wood trunk, branches, stumps and bark. Wood trunk gives the main economic benefit due to logging. All other wooden parts are usually seen as forest residues, although they are an important resource of biomass as well [10].

Considering that the annual production of biomass is 300000 billion tons, biomass is a large and theoretically unlimited resource. However, the production of biomass requires other natural resources, such as land, soil, water and nutrients [6]. Moreover, it is important to consider that the production of higher volume biomass takes a longer period of time, therefore, the implementation of effective and sustainable production, handling and recycling of biomass is crucial.

\subsection{The Annual use of Energy Wood in Europe}

The final consumption of renewables in the EU accounted for $17.5 \%$ of the total power consumption in 2017. The main resource of renewables was wood and other solid biomass and it accounted for $42 \%$ of the consumed renewables or $7.35 \%$ of total energy consumption [11].

TABLE 1. THE AMOUNT OF PRODUCED WOOD AND OTHER SOLID BIOMASS AND ITS SHARE IN RENEWABLES IN THE EU PER YEAR [11]

\begin{tabular}{lll}
\hline & Renewable energies, GWh/year & Wood and other solid biomass, GWh/year \\
\hline $\mathbf{2 0 0 5}$ & 1395 & 786 \\
$\mathbf{2 0 0 6}$ & 1468 & 805 \\
$\mathbf{2 0 0 7}$ & 1581 & 846 \\
$\mathbf{2 0 0 8}$ & 1690 & 891 \\
$\mathbf{2 0 0 9}$ & 1779 & 922 \\
$\mathbf{2 0 1 0}$ & 1962 & 1000 \\
$\mathbf{2 0 1 1}$ & 1923 & 954 \\
$\mathbf{2 0 1 2}$ & 2114 & 1029 \\
$\mathbf{2 0 1 3}$ & 2262 & 1049 \\
$\mathbf{2 0 1 4}$ & 2295 & 1012 \\
$\mathbf{2 0 1 5}$ & 2387 & 1065 \\
$\mathbf{2 0 1 6}$ & 2444 & 1092 \\
\hline
\end{tabular}

The use of wood and other solid biomass in energy sector has increased in recent years (Table 1). 


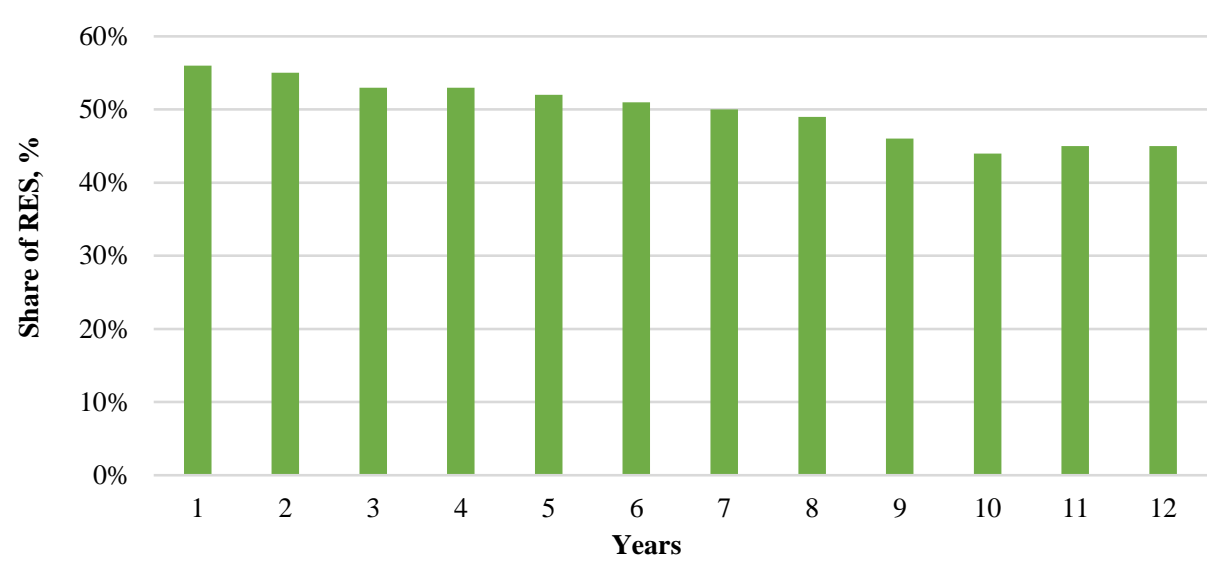

Fig. 1. Share of wood and other solid biomass in renewable energy in EU (2005-2016) [11].

However, the share of wood and other solid biomass (Fig. 1) use is declining against renewables [4], which can be explained by the more rapid increase in the use of other renewables, such as wind and solar power [11].

\subsection{Products with High Added Value}

It is expected that the price for $\mathrm{CO}_{2}$ emissions will grow in the near future, and the use of energy wood will increase. Whereas it will be more reasonable to use biomass instead of coal to produce energy, the competition between forest product industries and coal power plants for biomass will arise [12], [13]. Accordingly, it is expected that the increasing demand for energy wood will lead to an increase in prices for all wood products [14].

The increasing use of wood in energy sector is believed to reduce the negative impact on the environment; however, considering that energy wood is mostly also a potential resource for high value-added production, the principle of efficient and sustainable use of resources is not fully taken into account. A cleaner production of energy using bioresources, while at the same time ensuring sustainability, could be reached by using bioresources more effectively. This means that the qualitative wood and its useful components should first be used for high value-added production, while wood by-products or components, which are not suitable for this purpose, should be used for energy [15].

It is beneficial to primarily produce products with high added value, because that way it is possible to obtain not only classical wood products and fuel, but also food additives, fish and animal feed, textiles and various chemical compounds [16]. Products with high added value increase commercial interest as well, because along with the development of innovative technologies, many of them can be obtained at a reasonable cost and therefore ensure significant profit [17].

Energy wood consists of several base elements - cellulose, lignin, hemicellulose and other chemicals depending on the type of a tree [18]. Bark contains a lot of valuable biologically active compounds as well. Valuable chemicals can be obtained as a result of the synthesis of these compounds [10].

In recent years the research on the use of wood for production of different valuable materials and bioproducts has become increasingly relevant. For example, the potential use of lignin, the second largest component in biomass, is wide due to its unique characteristics. As research shows, lignin can be useful for obtaining various valuable materials, such as 
mixed hydrocarbon, alkylbenzenes, polymers, activated carbon, carbon fibers, mixed quinones, mixed phenols etc. [19]. Lignosulfonates, in turn, are used as additives in concrete mixtures. Their surfactant properties can be useful for production of agrochemicals, dyes, pigments coatings, textile lubricants, personal care products, detergent formulations and other products. In animal feed sector lignosulfates are used as animal feed binder, while they enrich feed with calcium and sodium. The use of lignin in production of polymeric materials and chemicals is even considered to be a potential solution towards a more sustainable world [20].

Besides the research on the use of wooden biomass, the research on the use of non-wood products has also become topical, which is particularly useful for more efficient use of resources. For example, terpenes, which are obtained from pine resins, are proved to have various applications in industry, such as chemicals, pharmaceuticals, agrochemicals, food additives and bioenergy. Moreover, the potential use of terpenes in production of biodegradable batteries and green plastics is proved. Other pine non-wood resources, such as needles, cones and bark can be useful in landscaping, plant cultivation substrates, biofuels and bioherbicides. Other uses include the production of medium density fiberboard, metal biosorption composites and nanofibrillated cellulose [21].

According to the latest tendencies in bioeconomics, waste is also seen as a resource [10]. This approach is particularly convenient because not only a new resource for obtaining valuable materials is implemented, but also the waste problem is being solved. In Europe around 33.7 thousand $\mathrm{m}^{3}$ of wood waste was generated from wood products in $2010,46 \%$ of which was recycled and $51 \%$ was burned. Considering the increasing attention brought to recycling and circular economy in Europe, wood waste can be seen as an important source of secondary raw materials. Furthermore, the great variety of wood type and its application make wood waste a very diverse material from the perspective of recycling [22].

The most common type of wood waste recycling is currently chipboard production. Depending on wood quality standards, other wood waste recycling options include production of woodchips and wood pallets, resource for combustion, composting, mulch production, animal bedding and pulping into paper products. Applications such as recycling into other wood based panels, wood composites and biobased chemicals have gained an increasing attention; however, the development of these applications is interfered by the poor quality of wood. Higher quality of wood waste could be achieved by improving separate collection, sorting and handling of wood waste. It is assumed that the production of chipboard will remain the primary option for wood waste recycling in the near future [22].

The need for a policy implementation for more efficient use of wood resources is recognised at the EU level, which is indicated by the European Commission study on the optimised cascading use of wood [23]. The study indicates several tasks to promote more efficient use of wood, such as developing EU standards for wood waste classification, creating a platform to share positive practices on cascading use of wood waste, improving the data on wood and wood waste applications and flows, ensuring that the material and resource-efficient use of wood is a central element in the potential development of the Bioeconomy strategy, enabling and supporting research activities to overcome specific technical barriers to cascading use etc.

\subsection{Forecast of Bioenergy use in Context of Long Waves}

The future development of technology and the breakthrough of innovation depends on several factors. As early as in the first half of the $20^{\text {th }}$ century (1920s), economic scientists developed the theory that the development of technology and innovation is cyclical or wavy (see Fig. 2). 


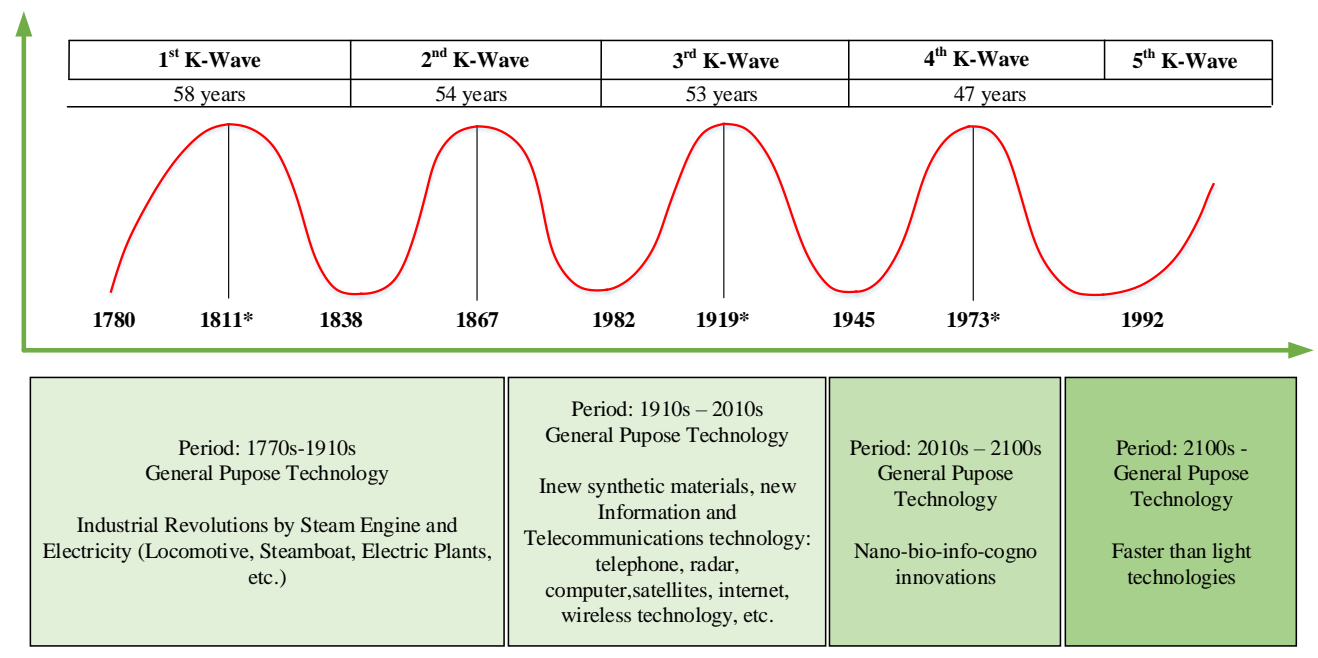

Fig. 2. Evolution of technologies for the dynamics of K-waves [24].

Kondratieff, the initiator of the long wave theory, has defined that one cycle is developing for about 55 years, and each cycle/wave - Kondratieff waves (acronym: K-waves) has different technology breakthroughs, see Fig. 3 [25]. Several scientists have conducted research on K-waves or long wave (LW) theory [25], [26].

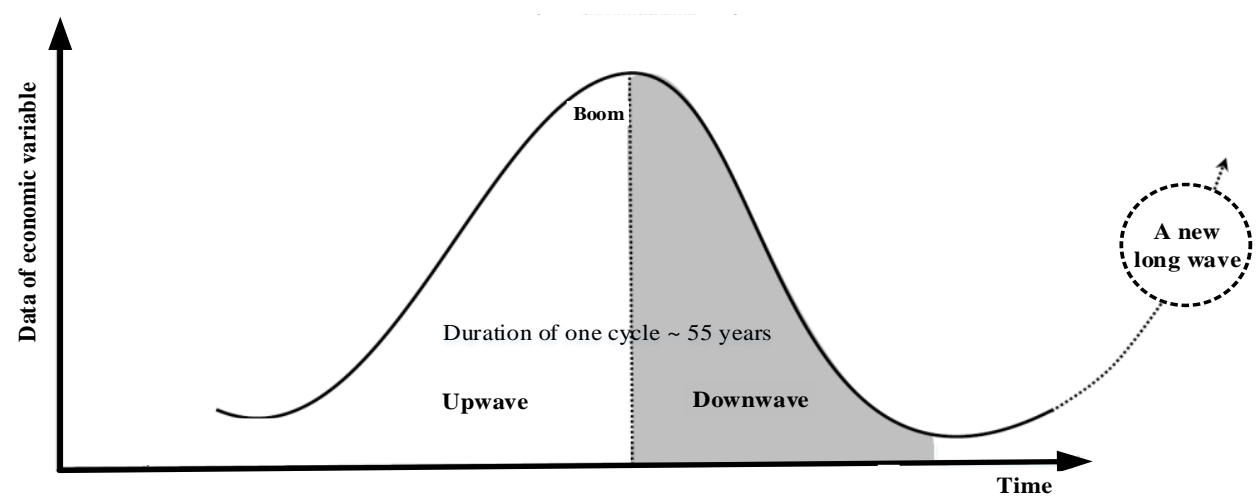

Fig. 3. Evolution of Kondratieff waves [27].

With regard to the future predictions using Kondratieff wave (K-waves) or Long Waves, there are two contradictory beliefs that the development is based on hegemonic wars that occur in the wave-rising phase, or that wavy development occurs independently of hegemonic wars [27]. It is emphasized that significant technological developments are taking place in the post-war phase.

Scientific research shows that long waves are based on technological transformations, stability, timing, economic factors, emerging technologies, technological breakthroughs, emerging technologies, and technological breakthroughs in the next K-waves [27].

However, it is difficult for existing theoretical systems to explain the general sources of LW due to the lack of comprehensive and consistent arguments. In fact, it is not known how long waves appear and develop. Especially, "what causes K-waves" depends also on "What 
is the why and how of major innovations, and why and when do they bunch?" [27]. There are suggestions that waves and their development can be linked to the wars, general purpose technology (GPT) and clusters of innovation. There is a hypothesis that the development of a new cycle in K-waves is influenced by wars between countries (great powers) as well as the development of general-purpose technologies and innovations. Impact factors change, but they are mainly related to the above mentioned three factors [27].

Some scientists, Devez and Corredine, on the one hand, emphasise that wave evolution could be based on biological determinants, i.e. "natural human biological clocks", which over time impose a rhythm of collective behaviour. Goldstein, on the other hand, tries to explain the relationship between factors such as war, production and innovation [27].

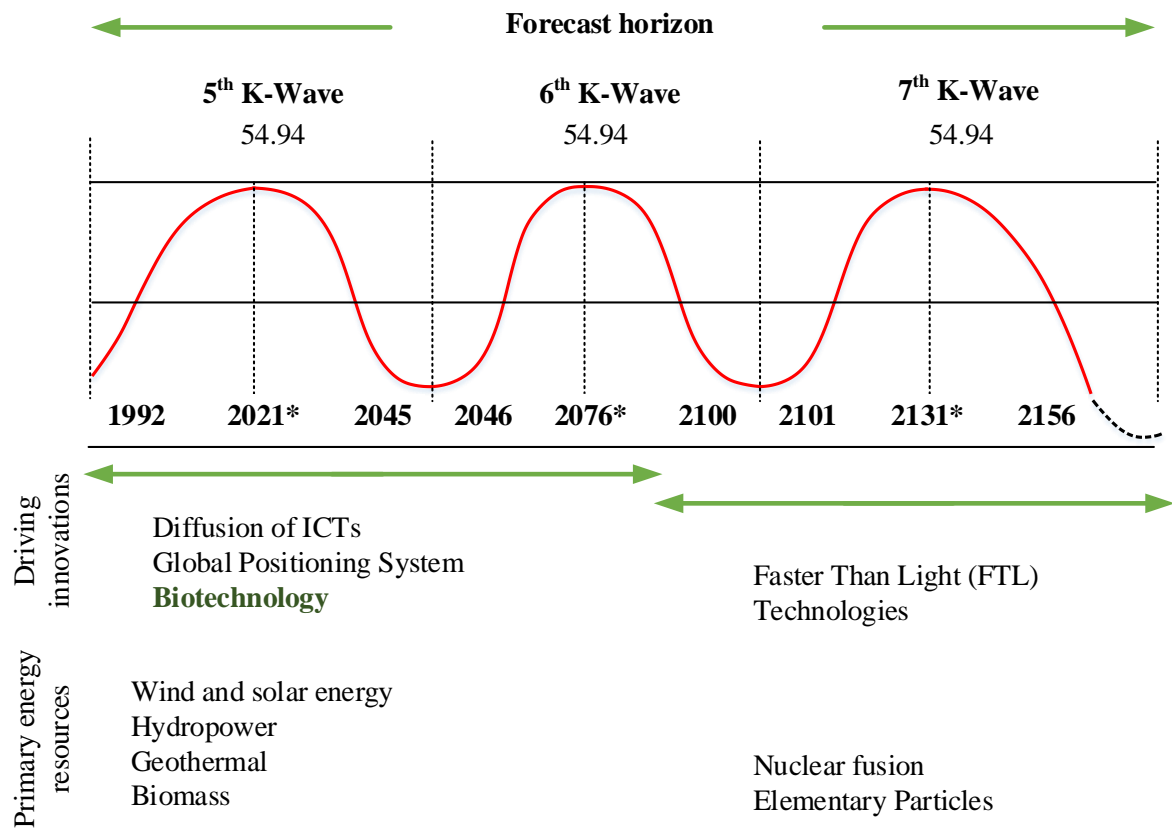

Fig. 4. Forecast of long waves, their driving technological innovations and primary energy resources [26], [27].

According the long wave theory, the "explosion" of innovations and technologies is expected over the next few years, and the most important technologies and achievements in the $5^{\text {th }}$ cycle will be diffusion of ICTs, global position systems and biotechnologies (see Fig. 4). As far as the development of primary resources is concerned, it is forecasted that the use of certain fossil resources (oil, gas) will continue. Renewable energy will be produced by wind and solar energy, hydropower, geothermal and biomass [26].

\section{Methodology of AnAlysis. Levelized Costs of Electricity}

In this scientific research, the research part is based on the levelized cost of electricity (LCOE) calculation. The analysis of literature reveals that biotechnology was predicted several decades ago. Nowadays the essence of bioeconomy has developed rapidly in several countries of the world, including Latvia. The mathematical calculation, taking into account 
different development scenarios, will show that it will be more profitable to use wood as a resource for products with high added value than for the production of energy.

\subsection{Energy from Biomass}

Biomass resources are diverse and can take many forms - manure, wood biomass, agricultural residues, municipal waste and sewage sludge. There are also varied possibilities for its use, end products and conversion or processing technologies. It can be used for obtaining various products - food, feed, materials and energy. In context of energy production, biomass can be conditionally divided into "traditional" and "modern" energy source. Traditional use of biomass for heat energy production is, for example, burning wood, which has been done since the very beginning of civilization. Modern uses of biomass include, but are not limited to, production of liquid fuel, biogas, wood pellets and bio-char [28].

While exploring possibilities to transform biomass into high added value products, the International Energy Agency "Bioenergy Task 42" [29] highlights several biomass transformation routes that produce electricity, heat and liquid fuel as side products, while producing various primary products. For example, sugar crops (sugar cane, sugar beets, wheat) biorefinery platform allows to produce bioethanol and animal feed. Oil biomass biorefinery - biodiesel and glycerine. Oil biorefinery has the potential to produce different chemicals and polymers as well. Gasification of lignocellulosic crops produces syngas for heat and electricity production or synthetic biofuel and polymers (rubbers). Biogas platform can possibly produce electricity, heat, biomethane and fertilizer. In these cases, economical assessment of a renewable energy resource must take into account additional benefits from selling the main product. This often reduces costs specifically for production of energy; however, technology costs might increase and there is less amount of raw material allotted specifically for energy production.

\subsection{Combustion of Biomass in Cogeneration}

Combustion of biomass is the oldest and most widely developed way to use biomass for energy production [30]. Biomass co-generation usually has high efficiency (over $80 \%$ ). Levelized cost of energy (LCOE) method historically has been widely used for economical assessment of electricity production from renewable resources [31]-[34]. Hansen [35] mentions that there is an extremely small number of sources in literature, where LCOE has been used for calculation of levelized cost of heat energy. As an example, where LCOE is used for the heat energy assessment, Hansen [35] mentions Sandvall et al. [36] paper on cost efficiency of urban heating strategies.

\subsection{Calculation of LCOE for Biomass Co-Generation}

LCOE as a method to assess the cost of electricity produced in biomass co-generation has been suggested by the "Guidelines for assessing the greenhouse gas impacts of renewable energy policies" published by New Climate Institute [37]. Guidelines indicate that LCOE of electricity from biomass cogeneration plant consists of sum of capital costs (I), operational and maintenance costs (OM) and fuel costs (F) minus income from heat utilization (REV), divided by the total electricity production $(\mathrm{E})$.

Simplified formula for calculation of LCOE for biomass co-generation is presented in Eq. (1) [37]. 


$$
L C O E=\frac{I+O M+F-R E V}{E}
$$

The standard formula for LCOE calculation [38] also includes the discount rate:

where

$$
L C O E=\frac{\sum_{t=1}^{n} \frac{I_{t}+O M_{t}+F_{t}}{(1+D R)^{t}}}{\sum_{1}^{n} \frac{E_{t}}{(1+D R)^{t}}},
$$

$I_{t} \quad$ Initial investment costs;

$O M_{t} \quad$ Annual costs for operation and maintenance;

$F_{t} \quad$ Fuel costs;

$E_{t} \quad$ Annual energy production;

DR Discount rate, \%;

$N \quad$ Economical life cycle of the plant.

Combining these two formulas authors choose to calculate LCOE using following equation:

$$
L C O E=\frac{\sum_{t=1}^{n} \frac{I_{t}+O M_{t}+F_{t}+R E V_{t}}{(1+D R)^{t}}}{\sum_{1}^{n} \frac{E_{t}}{(1+D R)^{t}}} .
$$

The results of calculations of levelized cost of energy (LCOE) is shown in the third chapter of this research paper, in which three development scenarios are described.

\section{RESULTS AND DISCUSSION}

\subsection{LCOE Results. Three Scenarios}

LCOE was calculated for the co-generation boiler plant with capacity $7 \mathrm{MW}$ and boiler efficiency of $86 \%$. It is assumed that the annual consumption of wood chips is $6.258 \mathrm{t}$, annual produced electricity $-1412 \mathrm{MWh}$, annual heat energy production $-19776 \mathrm{MWh}$.

Installation of co-generation system has been assumed to be 2578500 EUR based on Wood Energy company estimates (converted to EUR using currency conversion rate on $13^{\text {th }}$ of April 2019). Annual service costs, including4 on-site visits amounts to 4059.72 EUR [41]. Co-generation system parameters and costs are assumed based on cogeneration system costs for production company in United Kingdom as estimated by Wood Energy company [39].

To bring the results closer to the actual situation in Latvia, average he at price was estimated using the average consumer price in Latvia - 45 EUR/MWh. It is assumed that $45 \%$ of the price goes directly to the heat producer (the rest is made up of system services, taxes, etc.). The weighted average electricity price was estimated for 3 scenarios:

- Scenario 1 - current wood chip price in the market;

- Scenario 2 - wood chip price increase by $20 \%$;

- Scenario 3 - wood chip price increase by $40 \%$. 
In all the scenarios it was assumed that the operation of boiler systems is maintained by manpower which amounts to $735.96 \mathrm{EUR} / \mathrm{month}$.

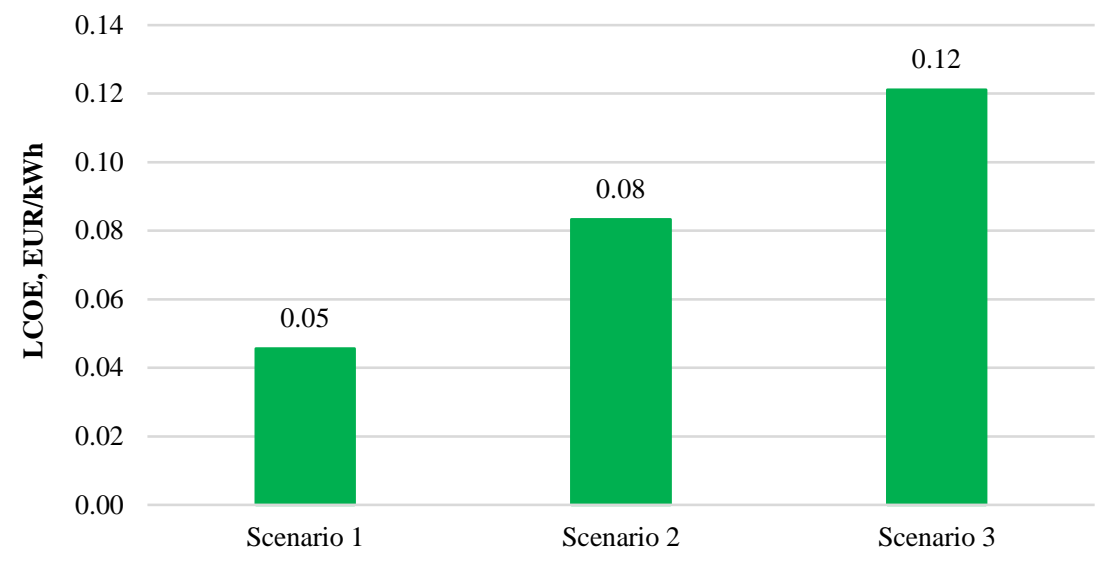

Fig. 5. Weighted average electricity price (LCOE) for woodchip cogeneration with a capacity of 7 MW.

Calculated Levelized Cost of Electricity is displayed in Fig. 5.

\subsection{Parameter Sensitivity Analysis}

To determine the cost category that has the biggest influence on LCOE of the electricity produced in wood chip cogeneration, parameter sensitivity analysis was performed (see Fig. 6).

The parameter sensitivity analysis shows that in this case LCOE of electricity is most affected by the price of utilised heat. This result can be explained by the fact that heat is the main product of the cogeneration in these scenarios, which means that the share of electricity in the final product is relatively small. The second factor that has the most significant impact on wood chips in LCOE is the price of fuel (wood chips).

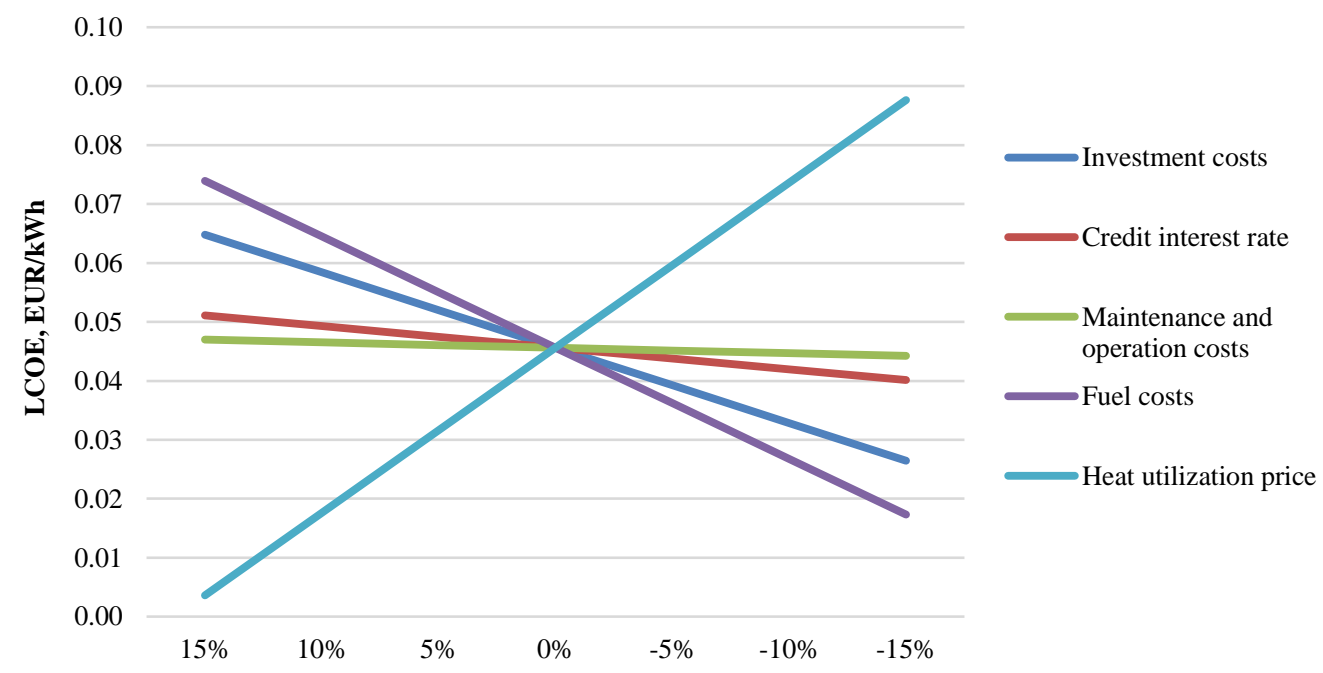

Fig. 6. Parameter sensitivity analysis. 


\subsection{Comparison of Electricity Costs}

The cost of electricity compared to solar, wind and biomass energy is illustrated in Fig. 7.

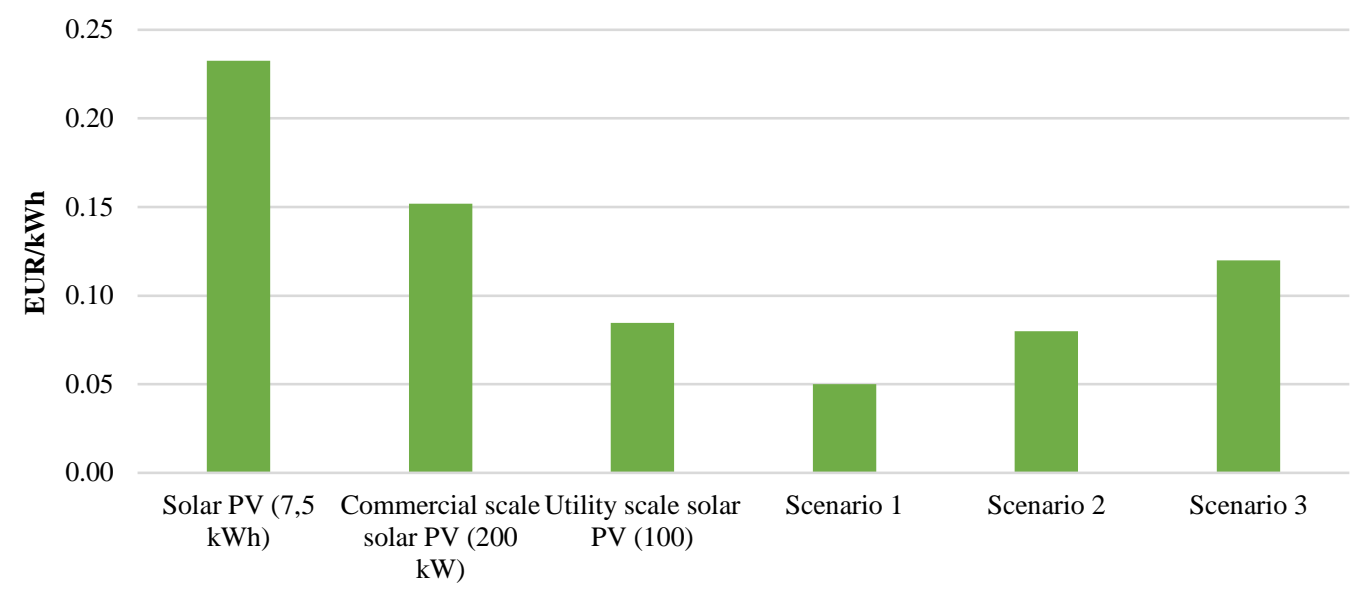

Fig. 7. Weighted average electricity price (LCOE) for renewable energy resources [40].

The values confirm that due to the development of bioeconomy, as the price of biomass resources increases, solar and wind power will supplant the burning of quality biomass from the electricity market.

\section{Conclusion}

As one of the main requirements regarding of sustainable resource use is to replace fossil fuels with renewable energy resources [41], [42], biomass is an essential pillar of the bioeconomy and it serves as its main resource [43]. In Europe, the consumption of wood and other solid biomass for energy generation is increasing every year. Based on an annual growth of about 300000 billion tons of biomass, biomass is a huge and theoretically unlimited resource.

The long wave theory predicts a sharp technological breakthrough for biotechnology over the next few years. In the context of the bioeconomy, it is analysed and successfully demonstrated that wood and other types of biomass are being increasingly used for products with high added value and the use of wood as a resource for energy will be decreased.

In order to confirm the claim that the use of wood as an energy resource will decrease, a levelled cost of energy was calculated. In order to assess the potential of the resource, three scenarios were developed for the use of energy wood: Scenario 1 - current wood chip price in the market; Scenario 2 - wood chip price increase by $20 \%$; Scenario 3 - wood chip price increase by $40 \%$. As the price for energy wood will increase, wood as a resource in the energy sector will not be sustainable. The price of energy wood as a resource per unit of energy is projected to increase from $0.04 \mathrm{EUR} / \mathrm{kWh}$ to $0.12 \mathrm{EUR} / \mathrm{kWh}$.

Although the price of energy wood is reduced by other renewable resources use, wood will in the future be used to produce products with high added value, leaving space for renewable resources like wind and solar energy. 


\section{ACKNOWLEDGEMENT}

This research is funded by the Latvian Council of Science, project "Blind spots in the energy transition policy (BlindSpots)", project No. lzp-2018/2-0022.

\section{REFERENCES}

[1] Wensing J., Carraresi L., Bröring S. Do pro-environmental values, beliefs and norms drive farmers' interest in novel practices fostering the Bioeconomy? Journal of Environmental Management 2019:232:858-867. doi:10.1016/j.jenvman.2018.11.114

[2] Menéndez A. J. L., Pérez R., Moreno B. Environmental costs and renewable energy: Re-visiting the Environmental Kuznets Curve. Journal of Environmental Management 2014:145:368-373. doi:10.1016/j.jenvman.2014.07.017

[3] Caineng Z., Qun Z., Guosheng Z., Bo X. Energy revolution: From a fossil energy era to a new energy era. Natural Gas Industry B 2016:3(1):1-11. doi:10.1016/j.ngib.2016.02.001

[4] Blumberga D. Biotehonomika (Biotechonomy). Riga: RTU Izdevniecība, 2016. (in Latvian)

[5] Björheden R. Drivers behind the development of forest energy in Sweden. Biomass and Bioenergy 2006:30(4):289-295. doi:10.1016/j.biombioe.2005.07.005

[6] Lewandowski I. Securing a sustainable biomass supply in a growing bioeconomy. Global Food Security 2015:6:34-42. doi:10.1016/j.gfs.2015.10.001

[7] European Union. Directive 2009/28/EC of the European Parliament and of the Council of 23 April 2009 on the promotion of the use of energy from renewable sources and amending and subsequently repealing Directives 2001/77/EC and 2003/30/EC. Official Journal of the European Union 2009:L140:16-62.

[8] WBA 2017. Global Bioenergy Statistics 2017 [Online]. Available: https://worldbioenergy.org/uploads/WBA\%20GBS\%202017_hq.pdf

[9] UNECE/FAO 2018. Joint Wood Energy Enquiry [Online]. Available: https://www.unece.org/forests/jwee.html

[10] Eurostat 2019. Renewable energy statistics [Online]. Available: https://ec.europa.eu/eurostat/statistics-explained/index.php/Renewable_energy_statistics

[11] Eurostat 2018. Primary production of renewable energy by type [Online]. Available: https://ec.europa.eu/eurostat/web/products-datasets/-/ten00081

[12] Lauri P., Kallio A. M. I., Schneider U. A. Price of $\mathrm{CO}_{2}$ emissions and use of wood in Europe. Forest Policy and Economics 2012:15:123-131. doi:10.1016/j.forpol.2011.10.003

[13] Moiseyev A., Solberg B., Kallio A. M. I. The impact of subsidies and carbon pricing on the wood biomass use for energy in the EU. Energy 2014:76:161-167. doi:10.1016/j.energy.2014.05.051

[14] Buongiorno J., Raunikar R., Zhu S. Consequences of increasing bioenergy demand on wood and forests: An application of the Global Forest Products Model. Journal of Forest Economics 2011:17(2):214-229. 10.1016/j.jfe.2011.02.008

[15] Muizniece I., Blumberga D. Wood resources for energy production sector in Latvia. Is it a sustainable solution? Energy Procedia 2017:128:287-291. doi:10.1016/j.egypro.2017.09.076

[16] Muizniece I., Gravelsins A., Brauners I., Blumberga A., Blumberga D. Innovative bioproducts from forest biomass. Method of analysis. Energy Procedia 2017:113:434-441. doi:10.1016/j.egypro.2017.04.035

[17] Budzianowski W. M. High-value low-volume bioproducts coupled to bioenergies with potential to enhance business development of sustainable biorefineries. Renewable and Sustainable Energy Reviews 2017:70:793-804. doi:10.1016/j.rser.2016.11.260

[18] Zorb C., et al. Biobased Resources and Value Chains. In: Lewandowski I. Bioeconomy. Shaping the Transition to a Sustainable, Biobased Economy. Cham: Springer, 2018.

[19] Wang H., Pu Y., Ragauskas A., Yang B. From lignin to valuable products - strategies, challenges, and prospects. Bioresource Technology 2019:271:449-461. doi:10.1016/j.biortech.2018.09.072

[20] Tribot A., Amer G., Abdou Alio M., de Baynast H., Delattre C., Pons A., Mathias J. D., Callois J. M., Vial C., Michaud P., Dussap C. G. Wood-lignin: Supply, extraction process and use as bio-based material. European Polymer Journal 2019:112:228-240. doi:10.1016/j.eurpolymj.2019.01.007

[21] Neis F. A., de Costa F., de Araujo Jr. A. T., Fett J. P., Fett-Neto A. G. Multiple industrial uses of non-wood pine products. Industrial Crops \& Products 2019:130:248-258. doi:10.1016/j.indcrop.2018.12.088

[22] Faraca G., Boldrin A., Astrup T. Resource quality of wood waste: The importance of physical and chemical impurities in wood waste for recycling. Waste Management 2019:87:135-147. doi:10.1016/j.wasman.2019.02.005

[23] Vis M., Mantau U., Allen B. Study on the optimised cascading use of wood. Final report. Brussels: European Commission, 2016. 
[24] The Federal Facilities Council Ad Hoc Task Group on Integrating Sustainable Design. Sustainable federal facilities: a guide to integrating value engineering, life-cycle costing, and sustainable development. Life-Cycle Costing, and Value Engineering into Facilities Acquisition. Federal facilities council technical report No. 142. Washington: National academy press, 2001.

[25] Kondratieff N. D., Stolper W. F. The long waves in economic life. The Review of Economics and Statistics 1935:17(6):105-115.

[26] Coccia M. Foresight of technological determinants and primary energy resources of future economic long waves. Int. J. Foresight and Innovation Policy 2010:6(4):225-232.

[27] Coccia M. A Theory of the General Causes of Long Waves: War, General Purpose Technologies, and Economic Change. Technological Forecasting \& Social Change 2018:128:287-295. doi:10.1016/j.techfore.2017.11.013

[28] IRENA. Bioenergy data [Online]. Available: https://www.irena.org/bioenergy

[29] The Biorefinery fact sheet. IEA bioenergy task 42 Biorefining [Online]. Available: https://www.iea-bioenergy.task42-biorefineries.com/en/ieabiorefinery.htm

[30] Jungmeier G., Van Ree R., de Jong E., Stichnothe H., de Bari I., Jørgensen H., Wellisch M., Bell G., Spaeth J., Torr K., Kimura S. The biorefinery fact sheet and its application to Wood Based biorefining. IEA bioenergy task 42 Biorefining.

[31] Stacy T. F., Taylor G. S. The levelized Cost of Electricity from Existing Generation Resources. Institute of Energy Research, 2015.

[32] Namovicz C. Assessing the Economic Value of New Utility-Scale Generation Projects. EIA LCOE/LACE Workshop, 2013.

[33] Lauka D. Sustainability analysis of renewable energy sources. PhD Thesis. Riga: RTU, 2018.

[34] U.S. Energy Information Administration. Levelized Cost and Levelized Avoided Cost of New Generation Resources in the Annual Energy Outlook, 2018.

[35] Hansen K. Decision-making based on energy costs: Comparing levelized cost of energy and energy system costs. Energy Strategy Reviews 2019:24:68-82. doi:10.1016/j.esr.2019.02.003

[36] Sandvall F., Ahlgren E. O., Ekvall T. Cost-efficiency of urban heating strategies - modelling scale effects of low-energy building heat supply. Energy Strategy Reviews 2017:18:212-223. doi:10.1016/J.ESR.2017.10.003

[37] Renewable Energy Guidance. Guidance for assessing the greenhouse gas impacts of renewable energy policies. Appendix A: Overview of LCOE Method for RE Sources. Verra: New Climate Institute, 2018.

[38] Wood Energy company Example financial projections [Online]. Available: http://www.woodenergy.com/media/77994/binder-brochure-low-res-v02.pdf

[39] Coccia M. The source and nature of general purpose technologies for supporting next K-waves: Global leadership and the case study of the U.S. Navy's Mobile User Objective System. Technological Forecasting \& Social Change 2017:116:331-339. doi:10.1016/j.techfore.2016.05.019

[40] International Renewable Energy Agency. Renewable Power Generation Costs in 2017. Abu Dhabi: International Renewable Energy Agency, 2018.

[41] Alam S. S., Nor N. F. M., Ahmad M., Hashim N. H. N. A Survey on Renewable Energy Development in Malaysia: Current Status, Problems and Prospects. Environmental and Climate Technologies 2016:17(1):5-17. doi:10.1515/rtuect-2016-0002

[42] Klavins M., Bisters V., Burlakovs J. Small Scale Gasification Application and Perspectives in Circular Economy. Environmental and Climate Technologies 2018:22(1):42-54. doi:10.2478/rtuect-2018-0003

[43] Höglmeier K., Steubing B., Weber-Blaschke G., Richter K. LCA-based optimization of wood utilization under special consideration of a cascading use of wood. Journal of Environmental Management 2015:152:158-170. doi:10.1016/j.jenvman.2015.01.018 